\title{
Basic Characteristics of the Genre of Narrative Poem in some Southeast Asian Countries
}

\author{
Le Thi Bich Thuy, Institute for Culture and Development, Ho Chi Minh National Academy of Politics, 135 \\ Nguyen Phong Sac Street, Cau Giay District, Hanoi, Vietnam, lebichthuyhcma@gmail.com
}

\begin{abstract}
Narrative poem is a term in the traditional literary genre that has long appeared in the literature of ethnic groups in the Southeast Asia. The Southeast Asia's narrative poem is not only a unique genre in the type of regional literature that is very popular and beloved with its residents, but also is a rich, diverse development genre in both quantity and quality, has a great position and role in the literary history progress of ethnic groups in the Southeast Asia. The article gives an understanding of the concept as Narrative poem in terms of theory and historical literature, using the method of comparing types, semiotics, interdisciplinary and multidisciplinary approaches, analytical and intuitive methods in literary research to study the basic characteristics of the genre of narrative poem in some Southeast Asian countries, typically scholarly narrative poems (written narrative poems). The research results show that some basic characteristics of the Southeast Asia's narrative poem genre of structure and plot have developed from the preservation of the structure of folk tales to new creation, ensuring logically, closely, gradually reducing the folk factor and increasing the scholarly element...
\end{abstract}

Keywords: features of genre; narrative poetry; literature; Southeast Asia.

$\begin{array}{lll}\text { Received: 09.12.2020 } & \text { Accepted: 10.01.2021 } & \text { Published: 05.02.2021 }\end{array}$

\section{INTRODUCTION}

The narrative poetry in each Southeast Asian country is formed at different times and circumstances. Consequently, it has not been possible to determine the time for appearing the narrative poetry of Southeast Asia. Through many studies, it is possible to identify the formation of Southeast Asian narrative poetry in the second half of the second millennium (from the fifteenth century to the nineteenth century), depending on the early or late appearance of feudal states in Southeast Asian countries. The literature of Southeast Asia in general and the narrative poetry, in particular, began to be studied in depth and had the results from the 50s of the twentieth century. Many studies and essays on Southeast Asian literature are generalized, covering a long historical period and many collections, according to each major topic. In some studies, researchers focused on the type of narrative poetry and initially made judgments about the features of Southeast Asian narrative poetry. In the Literature of Southeast Asian countries, Nguyen has emphasized the folk of the narrative poetry and the relationship between the folk, as well as the scholarly nature of the genre: "The biggest feature of this genre is a clever combination between oral and written literature, between the folk and scholarly. The narrative poetry is a genre of folk origin, so it is most popular among all genres of written literature" (Nguyen, 1983, p. 15-16). When surveying the narrative poetry of ethnic minorities in Vietnam, Phan Dang Nhat (Nong, 1997) has promoted the artistic characteristics of this type, and thus had the ability to express all the delicate and complicated feelings and attract the audience with interesting storytelling methods. People have learned the narrative and lyrical value of folk literature, combined in a new type, which is the narrative poetry, and in some cases, those two values have been cleverly combined in a work. Additionally, Bui and Ha (Bui \& Ha, 1997) have explained the concept of the poetry that the narrative poem is basically based on the narrative method with a system of events and plots to reveal the topic content. The plot in the narrative poem is similar to the plot of the drama, the novel, and so on. In the form of telling with the plot, the poet has conditions to go into the details, the events of the story, and the different aspects of social conflicts. Therefore, the narrative poem has the ability to reflect the rich aspects of social life. By this meaning, narrative poetry can be considered as a novel. On the other hand, due to the use of poetic language to express, from images, rhythms to poetic syntax, the narrative poetry identifies the differences from the novel. In this regard, Duc has affirmed that "the medieval literature of Southeast Asia is mostly half of history and half of the art. This period is still covered by prose, and the narrative poetry is popular. The narrative poems are mostly anonymous (in Vietnam, there are anonymous narrative poems)" (Duc, 2000, p. 33). Similarly, when studying Southeast Asian literature, Nguyen thinks that from the seventeenth century onwards, the narrative poetry becomes the decisive literature in Southeast Asia. This author affirmed that "In the 
seventeenth, eighteenth, and nineteenth centuries, the traditionally written literature reaches its peak. In Vietnam, there is The tale of Kieu and a series of other works. In Laos, there is Xinxay and many narrative poems. In Thailand, there is Khun Chang Khun Phaen, Phra Aphai Mani. There is a series of Hikayat, Sjair in Indonesia" (Nguyen, 1983, p. 12). Furthermore, Vo pointed out that the narrative poetry of prose poetry is more influenced by the Buddhism, but it also has the imprint of the creation of the artist (Vo, 1981). Through the research works, the scholars have had different perspectives, given different perspectives and approaches on Southeast Asia's narrative poem. From the perspectives of the genre of narrative poem, the article gives an understanding of the terminology of narrative poem in terms of theory and historical literature: Narrative poem is a literary genre in the system of works reflecting real life through the complete development of the protagonist's personality in relation to many other characters personalities. This completeness is created by the popular structure with the plot, the system of characters, the story situations, etc. The narrative poem reflects the life through the poems imbued with lyrical substance, uses the national language and poetry genre of each nation in the Southeast Asia.

The literature in Southeast Asia is very diverse and rich in genre. The research objective is to identify the theoretical basis of the genre of narrative poem and to learn some basic characteristics of the genre of narrative poem in some Southeast Asian countries in terms of structure, plot and art of using words, rhythm and poetry genre. To further understand the research objective, we want to distinguish the genre of narrative poem from other genres of literature and initially position the genre of narrative poem in the flow of regional literature.

\section{METHODS}

The article uses the comparative method "as a thinking manipulation, comparing literature as a research methodology" (Nguyen, 2011, p. 60) to learn the characteristics of the narrative poem genre and uses the method of type to demonstrate the similarities of genre among the cultures of nations; the semiotics method is used to analyze and explain the words to find the meaning hidden behind language and image messages to confirm the uniqueness of the works; the interdisciplinary and multidisciplinary approaches; and analytical method and intuitive method in literary research (Nguyen, 2006) are used to study the basic characteristics of the genre of narrative poem in some Southeast Asian countries: The Tale of Kieu and Luc Van Tien of Vietnam, Riemke and Tum Tieu of Cambodia, Xinxay and Kalaket of Laos, Phra Aphamani and Khun Chang Khun Phean of Thailand, Hikayat Hang Tuah of Malaysia.

\section{RESULTS}

\section{The structure and plot of Southeast Asia's narrative poem have developed from preservation of the structure of folk tales to new creation, ensuring logics, coherence, gradual reduction of folk element and increasing scholarly element.}

The narrative poem is the literary genre in the narrative method, including works with facts and plots, but is expressed in rhyme (poetry). The plot of the narrative poem sometimes tells the life of a character to overcome many difficulties and challenges to achieve a peaceful and happy life as The Tale of Kieu, which mentioned Thuy Kieu's struggles and fate in relation to nearly 30 other characters in the work. Xinxay told about the achievement of Xinxay with many divine and semi-divine characters. Khun Chang Khun Phaen was about the life of Khun Phaen. But there are also narrative poems that specified the lives of many characters, most of whom are two characters who must overcome challenges to get their happiness. In Riemke, Pre Riem had to overcome many challenges to create a feat, and Xeda had to go through many tribulations to protect her virginity, faith, and self-esteem. In Kalaket, Kalaket always struggled to achieve his happiness and Manichean also had to overcome the dangers and struggles to find her husband in the deep mountain forest. Prince Phra Aphay in Phra Aphai Mani used his miraculous flute to overcome the difficulties and challenges and Prince Xisuvan with high-qualified martial arts to set up resounding victories. The difficulties and challenges that the main characters have to go through can be derived from dark forces in society. The difficulties can be created by the dark forces that may be unique, such as Mrs. Phan (Tieu's mother) and father and son of the District Chief Arochun in Tum Tieu, is the father of the Manichean in Kalaket, is the old friend Khunchang in Khunchang Khunphean. The force caused suffering and separation between Pre Riem and Xeda in Riemke is the Second Royal Concubine Kaykexay, the Demon King Riep and the blind jealousy of Riem. In Xinxay, the enemies of Xinxay are the six concubines, six princes, the fortune tellers, the Demon Lord Kunphan, and King Nok. In Phra Aphaymani, the power opposing the princes is the rigid conception of King Xuthat, Mrs. Phixua xamut, Prince Utxaren's family. In Luc Van Tien, the interfering forces are Grand Preceptor, Trinh Han, Bui Kiem and Vo The Loan. In The Tale of Kieu, the forces that harmed and exiled Kieu are Tu Ba, Ma Giam Sinh, So Khanh, Hoan Thu. 
Hikayat Hang Tuah narrative poetry has a number of characters up to about 130 . The character called Hang Tuah represents a heroic person bringing the soul and spirit of the nation. Hang Tuah is the culmination of efforts in the heroic historical era of the people here. Hang Tuah is described as a hero who excelled in his talent and loyalty while Hang Jebat is the embodiment of treason. (Braginsky, 1990, p. 407) Although the Southeast Asian narrative poems are regarded of the struggle of a character or characters from the difficulties and challenges created by a dark force or dark forces, all have in the common that its plots always made up of stringing and connecting the destinies from many different lives. The main characters in the Southeast Asian narrative poems always undergo many difficulties, oppressions, dangers and challenges to be able to achieve a peaceful and happy life.

The plot of Southeast Asian verse novels was built with many events and episodes. The characters in the verse novels must overcome many difficulties, challenges at different times with different levels of continuous harshness to make the verse novel become thrilling and attractive. On the one hand, the work serves the purpose of the story to tell, to listen to, but at the same time to extend the reflection and the capacity of the work. Mostly, the structure of Southeast Asian verse novels is built according to the plot system of basic events: Meeting - Separating - Reuniting. This plot system is not always strictly obeyed by the authors of the verse novels, but it has a relatively stable nature. In the genres of verse novels borrowed from different origins, the authors of the verse novels of each country will choose to organize the different structure - plot. In which, the group of verse novels originated from folklore in accordance with the plot system with these events and kept the structure - the plot from the work that it borrowed. Especially, the ending part of the verse novels always has a good ending and fullness towards the main characters, good people are reunited and enjoy a peaceful and happy life as the wish of themselves, and the wicked characters and dark forces will be punished. Verse novels having themes borrowed from foreign literature, especially borrowed from ancient Indian epics, are used in the plot structure of Hero - Beauty - Demon with the power of folk re-making of Southeast Asian literature. At the same time, due to the process of ethnicization, localization, and the process of creative transition of Southeast Asian residents, the works of verse novels originating from foreign literary subjects have been selectively, innovatively, and creatively absorbed in accordance with the ideology and psychology of the natives. This creativity has shown the basic cultural and historical characteristics of each Southeast Asian nation, such as Riemke of Cambodia with Ramayana epic of India, and The tale of Kieu of Vietnam with The tale of Kim Van Kieu of China. Though verse novels that are based on real life are created later and have fewer numbers, they reflect the diversity and richness of culture - religious identity, ideology, and psychology of residents of each ethnic group in Southeast Asia in the process of building structures and plots. In particular, the autobiographical factor is quite a common phenomenon in this group of verse novels as the situation of Luc Van Tien in the work Luc Van Tien that has the life of the author Nguyen Dinh Chieu. The verse novel Tum Tieu exploited by Botum Matthe Xom from the true historical story occurred in the sixteenth century in Cambodia. Hikayat Hang Tuah tells the story of Hang Tuah, who is a legendary warrior, a hero who lives during the reign of King Shah Mansur of the Muslim Sultanate of Malacca in the $15^{\text {th }}$ century. Due to the plot of Meeting - Separating - Reuniting, the composition of Southeast Asian verse novels includes many chapters and paragraphs. At the beginning and the end of the verse novels, there are often many chapters and paragraphs with a few events and catastrophes. In which, the opening is often referred to as the character introduction, which is the starting point of the plot and the ending of the poem with the reunion events being the complete part of the character. Most events and catastrophes in the chapters and paragraphs having the content of separation and challenges to focus on expressing the topic content of the work.

The content of verse novels is often structured as a struggle from two opposing personality systems. Besides, it is the integration of non-plot content according to the author's intention, and it is clearly revealed through the author's comment - the narrator during the development of the plot. In Tum Tieu, the author has revealed the intention of teaching, propagating the Buddhist ethics and giving lessons to Tum and Pech. (Botum, 2000, p. 123). Usually, the author's comments are often expressed at the beginning of the work or at the end of the work. The tale of Kieu of Nguyen Du, which is a scholarly work of verse novels, considered the masterpiece of classical Vietnamese literature, has many verses discussing things related to Kieu, but through these verses, it also revealed the composing perspective of Nguyen Du. (Nguyen, D., 1999, p. 5).

Southeast Asian verse novels, especially for scholarly verse novels, the end the work does not completely coincide with the plot because of the appearance of lyrical comments outside the plot. At the end of the tale of Kieu, Nguyen Du has a lyrical comment to generalize and point out the philosophy of fate of the character. (Nguyen, D., 1999, p. 215).

In many verse novels, there are many poems serving as the content that links between sections of the work to complete a plot. This combination is sometimes chorus, repetitive, sometimes a phrase and 
sometimes a verse. In order to move the meaning of the story of Tum Tieu into another meaning, the author often uses transitional poems, such as: "Talking about this country that day". Or at the end of each chapter in the work Xinxay, the author often repeats the verses such as: "The Buddha's full honor here." In Luc Van Tien, the author has linked the content between the poems more flexibly through the transitional verses like "This is a long time later". In Riemke, the plot develops in the way of folk tales, so the verses are often linked together by phrases like "then at that time". (Vu, 1992, p. 76).

The structure - the plot of the verse novels also carries the folk elements expressed in the way of naming the work. Most of the Southeast Asian verse novels are named after the main character's name. So when approaching the work, the reader and the listener can understand the content of the work about: The tale of Kieu is a story about Kieu, The story of Luc Van Tien about the main character who is Luc Van Tien, The story of Tum Tieu is about the main character who is Tum, The story of Phra Aphai Mani is the story of the Phra Aphay, The story of Xinxay is the story of the victories of Xinxay, Riemke is the story of the prince Riem. Hikayat Hang Tuah tells the story of Hang Tuah, who is a symbol of the ideal of defending the independence of the nation and the country, "as a soldier of the fighting, fighting for the interests of the nation." (Nguyen, 2012, p. 662)

In addition, many Southeast Asian verse novels also preserve the structure of folk tales and deploy the plot in the following order: Introducing the character (presenting the character background of the name, country, situation). These events, catastrophes, and challenges are increasingly difficult, harsh, and dangerous. The characters fight against the evil forces, overcome the difficulties, dangers, and challenges of nature and society. The event of reuniting happens when the characters overcame difficulties, tried to win and have a happy ending.

\section{The Southeast Asia's narrative poem has combined folklore and scholarly element in building a character system, developing the personality of the characters associated with real life making the world of characters in narrative poem more diverse and richer}

Narrative poem is a literary genre reflecting life by narrative and character is the most basic element to reveal the theme of thought of the work. Through the creation of the character, the artist expresses his or her perception about a certain individual or a certain issue of reality. Characters are the basic means for the author to generalize the reality in the way of visualization and artisticization. In the narrative poem, there is always a system of characters divided into different types of characters: the protagonist, the villain, the main character, the minor character, the central character. Many narrative poems build the system of characters based on character and personality, such as: amateur - beautiful woman, talented man - beautiful girl, noble - ordinary people, victim - relief. The number of characters in each Southeast Asia narrative poem depends on Actual reflected real scope and content. The central character in the narrative poem is clearly portrayed in appearance, situation, action, personality, talent to the victories, complex and sophisticated manifestations in the inner life and often the main characters are also protagonists that express the centralized theme of thought of the work.

Thuy Kieu is the main character in The Tale of Kieu described in detail by Nguyen Du from the beauty of appearance, the beauty of the soul, and talent to the inner tears of the character during 15 years of wandering and suffering many hardships. The author describes Kieu as a beauty with a sharp beauty that makes flowers jealous, willow angry, and nature also envy. "Nice flower would envy her charming lips' freshness, willow leaves get angry with her eyebrows' greenness," and her beauty is clearly portrayed in the reviews and comments of other characters in the work. Nguyen Du through describing Kieu's eyes to express the beauty in the inner world, the personality of the character, Thuy Kieu has a pure soul and a sentimental heart. Thuy Kieu's talent reaches the ideal level according to the aesthetic conception of the feudal period, including both playing the moon lute, playing chess, writing poems, and painting. Especially, her talent for playing the moon lute has become a forte, outstanding gift to everyone.

In the narrative poem Tum Tieu, the protagonist reflected under many angles: The character appears under the objective view of the narrator. The character is considered in the evaluation of other characters and sometimes the character self-disclosure through dialogue or monologue. The beauty of each character is meticulously portrayed and clearly depicted in the evaluation of other characters. (Botum, 2000, p. 42).

In the narrative poem, the main character is always described the most fully and clearly and plays the "key role of the plot, holds the central position in expressing the topic, theme, and thought of the work" (Le, 2000, p. 193). In addition, the narrative poem also includes many minor characters "holding secondary position compared to the main character in the plot, in the process of deploying the topic, theme, and thought of the work" (Le, 2000, p. 199). The system of characters in the Southeast Asian narrative poem, whether they are protagonists or villains, male or female, ordinary people or kings, 
historical figures or gods, all of them help to promote the development of the plot, create the structure of the work to express the narrative of the work.

Characters in Southeast Asian poetry stories are portrayed in the appearance and personality or soul in the aesthetic viewpoint of the literary literature line, but also with folklore. The main characters are beautiful, soulful, talented, and kind. The villains are ugly and evil. Besides, in the poetry stories borrowed from folklore, using the motif of supernatural characters, many supporting minor characters have appeared in the form of talented animals to help the protagonists in the process of overcoming challenges. At the same time, the influence of folklore is also expressed by describing the birth of some characters associated with miraculous elements.

The smooth combination of folklore and erudition in Southeast Asian poetry stories has created works of attractive and thrilling elements, but still very close to the reality of diverse and rich life. When depicting the inner world of the characters, the authors cleverly describe the inner conflict of the character in many different levels. Sometimes, the character must go through an inner struggle, conflict, fierce and forced to act against his/her will. In the story of Phra Aphai Mani, Phra Aphay fluted to make Phixua xamut die of a broken heart when they met again, but then he felt regretful because she was the mother of his beloved son. In the story of Riemke, Xeda was deeply distressed and full of hatred when the prince Pre Riem suspected her love and loyalty. She was ready to step on the pyre to prove her innocence and purity. However, she was still banished to the forest a second time while she was pregnant (Duc, 2000 p. 136). In the story Xinxay, King Kutxalat's sister, Xumuntha, was captured by the demon lord as a wife, so she did not stop Xinxay from killing her husband, the demon lord Kum Phan, and the guards of the demon lord, but she cried painfully on the body of the husband (Tuyet, at al. 1981). In Hikayat Hang Tuah, Hang Tuah is willing to protect the King, suffering the loss of Tun Teja, who is engaged to consecrate to the King Malacca. Hang Tuah kills Hang Jebat, whose fellow to protect the court and show whose loyalty to the King.

\section{The language of narrative poem is folk-filled, rich, close to the people classes and is a way to express the lyrical nature of the genre}

In Southeast Asian poetry stories, the author's language is associated with lyrical emotions and often exposed directly in lyrical verses. The tale of Kieu was written by the author Nguyen Du with the whole plot from the outside literature, which is Kim Van Kieu, the story of Thanh Tam Tai Nhan. From a novel of chapters and episodes (consisting of 20 episodes), Nguyen Du created a poetry story filled with lyricity. Before the fate and suffering of Kieu, the other commented directly, expressing his feelings directly in the lyrical language. To emphasize the crimes of dark forces causing suffering for Thuy Kieu and her family, author Nguyen Du spoke directly to assess their actions, expressing the author's feelings in the verses with the use of the word "injustice" repeated 3 times (Nguyen, D., 1999). In The story of Kieu, Nguyen Du not only analyzed the psychology of the characters, but also analyzed his own psychology. This is also a common feature of many Vietnamese Nom poetry stories. Whatever position in the work, those verses also express the author's thoughts and feelings (Nguyen, D., 1999, p. 153).

In different lyrical passages, the authors of poetry stories have shown the emotions, vibrations, and the psychology of characters in many different levels by lyrical language. In the story Riemke, the author describes Pre Riem's joy and hope when he is close to his lover (Vu, 2003, p. 103). These are the growing nostalgia when separated from the lover in the poetry story Tum Tieu (Botum, 2000, p. 66). The loneliness of Phra Aphay and Xixuvan when wandering in the deep jungle in Phra Aphai Mani. (Luu, 1999).

The poetry stories of Southeast Asian poetry were born and developed from an extremely rich and long-lasting folk culture. The language of folklore appears a lot in Southeast Asian poetry stories. The storytelling language in the Southeast Asian poetry stories contains elements of folk, which are easy to understand, to remember, to be attached to and close to classes of people. In many erudite poetry stories, the folk, the simplicity of the language has contributed to affirming the value of the work. The poetry story of Phra Aphai Mani is highly appreciated by the researchers because "The verse of the work is popular, pure, easy to understand, beautiful, and complete as well" and Xun Thon Phu is considered a person with the great merit of "breaking the rigidity of the ancient poetry law, absorbing the fresh poems of the people, cleverly combining the royal poetry and the folk poetry..." (Luu, 1999, p. 159). Of language in the poetry story Luc Van Tien, author Nguyen Dinh Chieu "rarely uses events, uses few words of confusion, methods of changing the meaning, metaphor, exclamation... which are often found in Nom erudite stories. The language of Luc Van Tien is very rustic, simple, and it is the language that has just been spoken and made with movements heard and understood immediately" (Nguyen, L., 1999, p. 647). The alternate verses of the narrative poetry Hikayat Hang Tuah describe and exploit the heroic nature of the Hang Tuah character (Braginsky, 1990, p. 408). The work has become famous and popular because 
the characters herein have showed many profound national characteristics, satisfying the feelings and emotions of the readers.

The Southeast Asian poetry story also absorbs the artistic method of folklore, such as using an analogy, association, rhetoric devices in proverbs, and folk songs. In Tum Teav poetry story, in the section of response, when the nice couple meets each other again, the author used 8 motives of parallelism in Cambodia folklore, which were: Flower - bee, boat - margin, elephant - cane, fish - river, bird - tree, tiger - cave in the forest, wild beast - dewdrop, beehive - honeybee (Botum, 2000, p. 79). In Phra Aphai Mani poetry story, many verses were borrowed ideas from Thailand proverbs (Luu, 1999). In The Tale of Kieu, many verses were created from Vietnamese folk songs by the author (Nguyen, D., 1999). Sometimes the author of poetry story uses the popular language, daily speech of people and elaborates, re-arranges, and enhances. The author of poetry story also uses many rhetorical devices, such as personification, so that the scenes show the character's feelings and emotion (Botum, 2000, p. 65). Sometimes the author also uses metaphor and metonymy devices to enrich the image (Nguyen, 2002, p. 69).

In the process of creation, making verse more profound, subtle, and solemn, the authors of the Southeast Asian poetry story also used literary allusion, classic reference, and borrowed foreign words. Sometimes, literary allusions and classic references used in poetry story could be taken from a historical legend, folk tales, the perception of people on subjects and phenomena in human's life or literary allusion borrowed from a foreign country. In the verses of The Tale of Kieu, author Nguyen Du used the number of Sino - Vietnamese words accounting for 35\% of the total number of words of this work (Tran, 2002). In the story of Luc Van Tien, Nguyen Dinh Chieu allowed Mr. Quan to talk about 11 classic references in his words to heap insults on Vo The Loan and her father.

In Southeast Asian poetry, the natural image is considered as an artistic language that appeared in many works. The number of writings and verses on nature is not much, but they play an essential role in describing the feelings, emotions, and mental states of the characters, especially the protagonists and contributing to the success of the work. In The Tale of Kieu by Nguyen Du, there are 222 verses of nature description, which are considered the best verses of Vietnamese national literature. The appearance of these verses is centered around describing the psychological and emotional state of the leading character.(Phan, N., 2001) In the story of the poem Tum Tieu of Cambodia, there are 117 verses describing nature and natural images that appear only with the two main characters, Tum and Tieu. (Botum, 2000, p. 116). In Tum Tieu that has verses that make readers and listeners difficult to identify the boundaries, which is the language of the character and which is the language of the author because the poetic words are very fussy, both rich in images and inspiration. (Botum, 2000, p. 148) The poetry, Xinxay of Laos, has nearly 5,500 verses, of which 1,000 verses in the work are the portrayal of nature. Nature's image is always associated with people's mood, feelings, and emotions. Xinxay's story became the masterpiece of Lao national literature when portraying national cultural nuances, the inner life of the inhabitants here. In the fluent Lao language, skillful verses, the paragraph describing jungle scenes has become the epitome of traditional Lao poetry. (Tuyet et al., 1981, p. 262-263). In Kalaket, many poems are filled with the natural images. (Tuyet et al., 1981)

The natural language is a typical characteristic of the lyrical aspect of Southeast Asian poetry. The appearance of natural images in poetry has shown the mood and emotion of the lyrical ego, and lyrical character.

\section{The Southeast Asia's narrative poem has its own rules about rhythm and poetry genre because of the psychological characteristics and cultural identity of each ethnic group.}

Each Southeast Asian nation has its own traditional poetic forms expressing the cultural identity and soul of the people. Various forms of national poetry have been used to convey different content, corresponding to the function of poetry. Riemke and Tum Tieu poems have been used by Cambodian authors to use the form of folk poetry very cleverly to suit the psychology of inhabitant. Cambodian poetry stories are very rich in verse with prosody, rhyming that lead to the sustainability of style of poetry. Riemke is a poeticstory with themes and plot originating from abroad, and that is the Indian epic Ramayana. The Ramayana epic when entering Cambodia was civilized, dissolved, and linked to many other forms of art and then became Riemke. The work has been handed down in long-term folklife, so it has appeared in many highly functional styles of poetry. When it comes to expressing indignant scenes, conflicts, war, fear scenes, or use in the instructor scene, you use the Xomna style (including 3 sentences: the first sentence is 7 syllables, the middle sentence is 5 syllables, the last sentence is 6 words). When expressing the separation full of pitiful scenes, use the Piliep style (including 3 sentences: the first is 8 words, the middle sentence is 5 words, the last one is 6 words). In addition to the Riemke, the writer also used many other styles of poetry, such as Promkate, Bontonkat (Vu, 1992). In a dialogue, the writer often uses the 4-word style of poetry, the 5 and 6-word style of poetry is used to depict sadness and loneliness, the Phuchuonglilia style 
of poetry is used to describe the natural landscape, and Pumnol style of poetry can be used to describe the mood of a cheerful character or thrilling circumstances. In each work, the writer uses many different styles of poetry, but the traditional style of poetry - 7 words are mostly used and loved by the inhabitant. In the Riemke, the functionalism of poetry is still high, as the work will be changed and supplemented to suit the history and psychology of the people in each period through each period of history. (Vu, 2003, p. 94). The poetic story Tum Tieu, is used in the traditional style of poetry of 7 syllables that are very loved by Cambodians. This style of poetry has fully shown the different functions when it is necessary to describe the emotions, the ideological emotional states, and different moods of the characters, such as joy - sadness, longing - memory, angry, meeting - separation, scene - love. This is a great development, demonstrating the great innovation of the genre in Cambodian poetry. (Vu, 2003)

Vietnamese poetry has used many different styles of poetry, but the lục bát ("six-eight") meter is the most traditionally used and occupied the unique position in the poem. In some poems of ethnic minorities, the authors still use many different styles of poetry to express the identity of each ethnic group. The Tale of Kieu by Nguyen $\mathrm{Du}$ is the pinnacle, the crystallization of the use of the traditional Vietnamese style of poetry - the poetic form: the lục bát ("six-eight") meter (Nguyen, D., 1999). Luc Van Tien is a famous work using the vernacular chũ Nom script by Nguyen Dinh Chieu written in lục bát because it is printed many times, so there are many different texts, sometimes adding or reducing hundreds of verses. According to the current commonly used text, the story has 2082 verses, structured according to the chapter and period (Nguyen, 2002).

The Xinxay poetry of Laos used the traditional poem of the nation, so it was widely circulated in all classes and enjoyed by the inhabitants. The richness of the "Kon an" style of poetry in Xinxay with its rhythmic structure and diverse rhyming, which makes the work an epitome of poetic use. Today, in the folk songs of Laos, such as Lam, Khap, or the interchange of the love of Laotian boys and girls performing at the festivals, they often echo the mighty poems, showing the iron will of the central hero characters of the Xinxay.

In Thailand, Lakhonnay can be used in Khun Chang Khun Phaen and still used in folk theater. The traditional style of poetry of the nation is an eight-syllable style of poetry, which is used in the Phra Aphai Mani.

A typical traditional style of poetry in Southeast Asian countries is still in use today. During the development of the poem, the model of national poetry has been more and more creative, and the poem has used a traditional poem that is loved and received by many people.

\section{CONCLUSIONS}

The Southeast Asia's narrative poem has the structure, plot and art of building the characters system which is a combination of folk and scholarly element, a rich narrative poem language close to the people classes and the specific rules of rhythm and poetry genre expressing the psychological characteristics and cultural identity of each nation are outstanding features to distinguish narrative poem from other literary genres. In the work of poetry in Southeast Asia, there is always a combination of narrative and lyricism, between folk and piety, folk lyric and scholarly lyric, between folk and a scholarly style. These artistic elements play a key role in bringing Southeast Asian poetry stories to the region's leading literary position. In the development of poetry, more and later, the combination of narrative and lyricism, between folk and scholarly that becomes more and more clever, so it brings more artistic success and more skillful works. The structure and plot are more diverse and attractive; characters are more complex and vigorous. The content of poetry stories from mysterious, distant stories, exploiting ancient books, borrowing from foreign works has come to stories about real life in ordinary people's lives, conflicts, and tragedies in real life. Situations and events are closer to real life. The poetic language is more and more subtle, close, easy to go to the hearts of people. This is the continuous movement of the genre to occupy the central and leading position of Southeast Asia traditional literature.

\section{REFERENCES}

Botum, M. X. (2000). Tum Tieu. Hanoi, Vietnam: Social Science Publishing House.

Braginsky, V.I. (1990). Hykayat Hang Tuah: Malay Epic and Muslim Mirror, Bijdragen tot de Taal, Land en Volkenkunde.

Bui, V. N. \& Ha, M. D. (1997). The Styles of Poetry and the Development of Forms in Vietnamese Literary Poetry. Hanoi, Vietnam: Social Science Publishing House.

Duc, N. (2000). Literature in Southeast Asia. Hanoi, Vietnam: Vietnam National University Hanoi Publishing House. 
Le, B. H. (2000). Dictionary of Literary Terms. Hanoi, Vietnam: Vietnam National University Hanoi Publishing House.

Luu, D. T. (1999). Literature of Southeast Asia. Hanoi, Vietnam: Education Publishing House.

Nguyen, D. C. (2002). Luc Van Tien. Da Nang, Vietnam: Da Nang Publishing House.

Nguyen, D. N. (Chief editor) (2012). Historical Dictionary of Malaysia, Social Sciences Publishing House, Hanoi.

Nguyen, D. (1999). Truyen Kieu. Hanoi, Vietnam: Literature Publishing House.

Nguyen, L. (1999). Vietnamese Literature (the second half of the eighteenth century to the end of the nineteenth century). Hanoi, Vietnam: Education Publishing House.

Nguyen, T. D. (1983). Literature of Southeast Asian countries. Hanoi, Vietnam: Southeast Asian Institute.

Nguyen, V. D. (2006). Methodology of Literature Study. Hanoi, Vietnam: Social Sciences Publishing House.

Nguyen, V. D. (2011). Comparative Literary Theory. Hanoi, Vietnam: Social Sciences Publishing House.

Nong, Q. C. (1997). Literature of Ethnic Minorities in Vietnam. Hanoi, Vietnam: National Cultural Publishing House.

Phan, N. (2001). Learning on the Style of Nguyen Du in the Tale of Kieu. Hanoi, Vietnam: Youth Publishing House.

Tran, D. S. (2002). Metrics of the Tale of Kieu. Hanoi, Vietnam: Education Publishing House.

Tuyet, P., Dinh, K. C., Vo, Q. N., \& Nguyen, N. (1981). Laotian Literature Collection. Hanoi, Vietnam: Literature Publishing House.

Vo, Q. N. (1981). Exploring Laos History - Literature (Episode 2). Hanoi, Vietnam: Social Science Publishing House.

Vu, T. L. (1992). Riemke and Tum Tieu in Cambodian Literature. Hanoi, Vietnam: Literature Publishing House.

Vu, T. L. (2003). A Collection of Cambodian Literature. Hanoi, Vietnam: Social Science Publishing House. 